\title{
Optimization of Submerged Arc Welding Parameters for Joining Dissimilar Materials Using Taguchi Method
}

\author{
Sandeep Kumar ${ }^{1}$, Er. Deepak Gupta ${ }^{2}$ \\ ${ }^{1}$ M.Tech. Student, Deptt. of M.E., Galaxy Global Educational Trust's Group of Inst., Ambala, India \\ ${ }^{2}$ Asst. Professor, Deptt. of M.E., Galaxy Global Educational Trust's Group of Inst., Ambala, India
}

\begin{abstract}
Submerged arc welding process is very important component in many industrial organizations. The research on factors controlling weld bead profile in SAW process is essential to high quality welding procedures. Quality is very important element in today's manufacturing world. Experiments are conducted using SAW process parameters viz. welding current, arc voltage and welding speed on dissimilar materials of $10 \mathrm{~mm}$ thickness to study these parameters on weld bead width and weld bead hardness. The experiments are designed using $L 8$ orthogonal array considering two factors and three levels.
\end{abstract}

Keywords: Submerged Arc Welding, ANOVA, Design of Experiments, S/N Ratio.

\section{Introduction}

Submerged arc welding process is very important component in many industrial organizations. The research on factors controlling weld bead profile in Submerged Arc Welding process is essential to high quality welding procedures. The submerged arc welding parameters are the most important factors affecting quality, productivity and cost of welding joint. Weld bead shape, size and hardness are important considerations for design and manufacturing engineers in fabrication industry. In fact weld geometry directly affects the complexity of weld schedules and thereby the manufacturing costs of steel structures and mechanical devices. Therefore, these parameters affecting the weld bead geometry and hardness should be estimated and their changing conditions during process must be known before in order to obtain optimum results; in fact a perfect arc can be achieved when all the parameters are in conformity. The various parameters like welding current, arc voltage, welding speed, type of current, torch angle and the electrode stick out are affecting the weld quality and hardness. Y.S. Tarng et al.[1] Through their study they show that the performance characteristics of SAW process such as deposition rate and hardness are improves together by using gray relation. N. Murugun et al.[2] through their study on prediction and control of weld bead geometry and shape relationships in Submerged Arc Welding of pipes they concluded that Arc voltage had a less significant negative effect on penetration and reinforcement but had a positive effect on bead width, penetration size factor and reinforcement form factor. T. Kannan et al.[3] concluded weld bead width increases with increase in welding current. Penetration increases with increase in welding current and speed and decreases with increase in nozzle to plate distance. Deepak Choudhary et al.[4] found that penetration increases significantly with current, decreases with welding speed and remains unaffected by open circuit voltage \& nozzle to plate distance. Weld bead width was found to increase with open circuit voltage, decrease with welding speed. The adequacies of the models were tested by use of analysis of variance. Rati Saluja et al.[5] Finds that Welding current and welding speed have major influence on bead penetration whereas electrode stick out has minor effect. Welding speed and electrode stick out had little or negligible effect on weld reinforcement. Pranesh et al.[6] had studied the effect on penetration depth of mild steel by SAW process. The results shows penetration will be at maximum value when welding current and arc voltage are at their maximum possible value and welding speed is at its minimum value. Deepti Jaiswal[7] presented the effect of controllable process variable on the heat affected zone (HAZ) for bead on joint welding. He concluded that the micro hardness of weld metal and HAZ decreased when the number of passes increases that is total heat input increased. Pratik umrigar \& Sandip Chaudhry [8] analyzed the effects of Plate thickness, Arc voltage and welding speed on Penetration and Bead width. The researchers concluded that plate thickness have most significant effect on penetration and bead width. Farzeen Shahid et al.[9] concluded that major problem occurs with dissimilar welding is formation of inter-metallic compounds at the interface which affect the properties and efficiency of the weld. And in order to improve the strength of dissimilar metal weld intermediate layers at the interface can be used. Sukhbaj Singh et al.[10] concluded that welding current have most significant effect on weld bead hardness. A.M. Moshi et al.[11] reviewed effects of process parameters on quality of welding because of its inherent benefits such as higher metal deposition rate, good strength of the joint and good surface appearance. The researchers concluded that SAW process is not recommended where a weld deposit is needed that is fully austenitic or is controlled on low ferrite content. 


\subsection{Taguchi Method}

Taguchi's philosophy is an efficient tool for the design of high quality manufacturing system. Dr. Genichi Taguchi, a Japanese quality management consultant, has developed a method based on orthogonal array experiments, which provides much reduced variance for the experiment with optimum setting of process control parameters. Orthogonal array provides a set of minimum experiments run and Taguchi's signal-to-noise ratios, which are logarithmic functions of desired output, serve as objective functions of optimization. This technique helps in data analysis and prediction of optimum results. To evaluate optimal parameter settings, Taguchi method uses a statistical measure of performance called signal-to-noise ratio. The signal-to-noise ratio is the ratio of the mean (signal) to the standard deviation (noise). The standard $\mathrm{S} / \mathrm{N}$ ratio generally used is as follows: Nominal-is-Best (NB), Lower-the-Better (LB) and Higher-the-Better (HB). The optimal setting is the parameter combination, which has the highest $\mathrm{S} / \mathrm{N}$ ratio.

\subsection{Process parameters levels}

\section{Experimentation}

The process parameters of submerged arc welding are welding current, Arc voltage, welding speed, wire diameter, electrode stick out, flux, heat input, polarity and type of current (AC or DC). Welding current directly influence the weld bead width and extend of base metal fusion. The welding arc voltage has direct influence on the shape of the bead, weld bead hardness and external appearance of bead. The travel speed has pronounced effect on weld size for given combination of current and arc voltage. Careful attention is necessary to select the welding process parameters to obtain a desirable weld quality. Though many direct and indirect parameters affect the quality of weld in submerged arc welding the major key process parameters affecting the bead geometry are welding current, arc voltage and welding speed. In the present study, two levels of 3 process parameters, i.e., current, voltage and speed was considered. The values of the welding process parameters at different levels are given in table 1

Table 1. Process parameter levels

\begin{tabular}{|l|l|l|l|}
\hline Level & $\begin{array}{l}\text { Voltage } \\
(\mathrm{vol})\end{array}$ & $\begin{array}{l}\text { Current } \\
(\mathrm{amp})\end{array}$ & $\begin{array}{l}\text { Speed } \\
(\mathrm{m} / \mathrm{h})\end{array}$ \\
\hline 1 & 25 & 420 & 25 \\
\hline 2 & 30 & 450 & 30 \\
\hline
\end{tabular}

The experiments are designed using L8 orthogonal array. The experimental layout for the welding process parameters using L8 orthogonal array and experimental results for the weld bead geometry using the L8 orthogonal array are shown in Table 2.

\subsection{Procedure}

The experiments are done on Submerged Arc welding Machine, Model Tornado, M 800 transformer and FD10-200T welding tractor available at MMU, Mullana. The copper coated Mild Steel wire with $3.2 \mathrm{~mm}$ diameter is used as electrode. The experiments are done on SS-304 and MS plates of $100 \times 50 \times 10 \mathrm{~mm}$ dimensions. The nozzle to plate distance is $20 \mathrm{~mm}$ and kept constant. Direct current electrode positive polarity is used. The Flux used is EN8. 45 degree v-groove joint is selected to fill the joint with $1 \mathrm{~mm}$ gap between both the work pieces. Weld bead width were measured by using a scale and weld bead hardness were tested by Rockwell Hardness Tester available at galaxy global educational trust's group of institutions. One measurement for each run was made for weld bead width and two measurements for each run for weld bead hardness. The mean value of both the measurements of weld bead hardness were taken as mean for weld bead hardness. The observed values of the responses are given in Table 2 .

Table 2. L8 orthogonal array design and output responses

\begin{tabular}{|l|l|l|l|l|l|}
\hline Run & $\begin{array}{l}\text { Voltage } \\
(\text { Vol.) }\end{array}$ & $\begin{array}{l}\text { Current } \\
(\mathbf{A .})\end{array}$ & $\begin{array}{l}\text { Speed } \\
(\mathbf{m} / \mathbf{h})\end{array}$ & $\begin{array}{l}\text { Width } \\
(\mathbf{m m})\end{array}$ & $\begin{array}{l}\text { Hardness } \\
(\text { HRC) }\end{array}$ \\
\hline 1 & 25 & 420 & 25 & 10.5 & 40.5 \\
\hline 2 & 25 & 420 & 30 & 10 & 39.5 \\
\hline 3 & 25 & 450 & 25 & 11 & 46.5 \\
\hline 4 & 25 & 450 & 30 & 12 & 45 \\
\hline 5 & 30 & 420 & 25 & 12 & 44.5 \\
\hline 6 & 30 & 420 & 30 & 9.5 & 47.5 \\
\hline 7 & 30 & 450 & 25 & 13.5 & 48.5 \\
\hline 8 & 30 & 450 & 30 & 11.5 & 47.5 \\
\hline
\end{tabular}


3.1 Signal-to-Noise Ratio (S/N Ratio)

\section{Analysis And Discussion}

To evaluate optimal parameter setting, the Taguchi method uses a statistical measure of performance called signal-to-noise ratio. The $\mathrm{S} / \mathrm{N}$ ratio developed by Dr. Genichi Taguchi is a performance measure to select control levels that best match with noise. The $\mathrm{S} / \mathrm{N}$ ratio takes both the mean and variability into account. The $\mathrm{S} / \mathrm{N}$ ratio is the ratio of mean (signal) to standard deviation (noise). The standard $\mathrm{S} / \mathrm{N}$ ratios generally used are as follows: nominal-is-best, lower-the-better, higher-the-better. In this paper, the characteristics values are selected by weld bead width and weld bead hardness. Since a good result is obtained by the smaller bead width and higher bead hardness. Hence for bead width L.B. is preferred and for weld bead hardness the H.B. signal-tonoise ratio has been selected.

\subsubsection{Analysis of $\mathrm{S} / \mathrm{N}$ ratio for bead width}

Smaller bead width is the desirable property of the weld bead joint. So in case of weld bead width, Smaller-the-better option has been chosen for the calculation of S/N ratio. From table 3, it has been analyzed that the parameter welding current is the most significant factor which affect the bead width. Optimal parameters setting for smaller bead width is, voltage $=25 \mathrm{~V}$, current $=420 \mathrm{~A}$, speed $=30 \mathrm{~m} / \mathrm{h}$.

Table 3.Response table for $\mathrm{S} / \mathrm{N}$ ratio $(\mathrm{SB})$

\begin{tabular}{|l|l|l|l|}
\hline Level & voltage & Current & Speed \\
\hline 1 & -20.71 & -20.39 & -21.36 \\
\hline 2 & -21.24 & -21.56 & -20.59 \\
\hline Delta & 0.53 & 1.17 & 0.77 \\
\hline Rank & 3 & 1 & 2 \\
\hline
\end{tabular}

\subsubsection{Analysis of $\mathrm{S} / \mathrm{N}$ ratio for bead hardness}

Higher bead hardness is a desirable property of the weld bead joint. Because it provide strength to the weld bead joint. So, for bead hardness, higher-the-better option is chosen for signal to noise ratio calculations. From table 4 , , it has been analyzed that the parameter welding voltage is the most significant factor which affect the bead width. Optimal parameters setting for higher bead hardness is, voltage $=30 \mathrm{~V}$, current $=450 \mathrm{~A}$, speed $=25 \mathrm{~m} / \mathrm{h}$.

Table 4.Response table for $\mathrm{S} / \mathrm{N}$ ratio(HB)

\begin{tabular}{|l|l|l|l|}
\hline Level & voltage & Current & Speed \\
\hline 1 & 32.62 & 32.64 & 33.04 \\
\hline 2 & 33.44 & 33.41 & 33.01 \\
\hline Delta & 0.81 & 0.77 & 0.03 \\
\hline Rank & 1 & 2 & 3 \\
\hline
\end{tabular}

\subsubsection{Main effect plot for bead width}

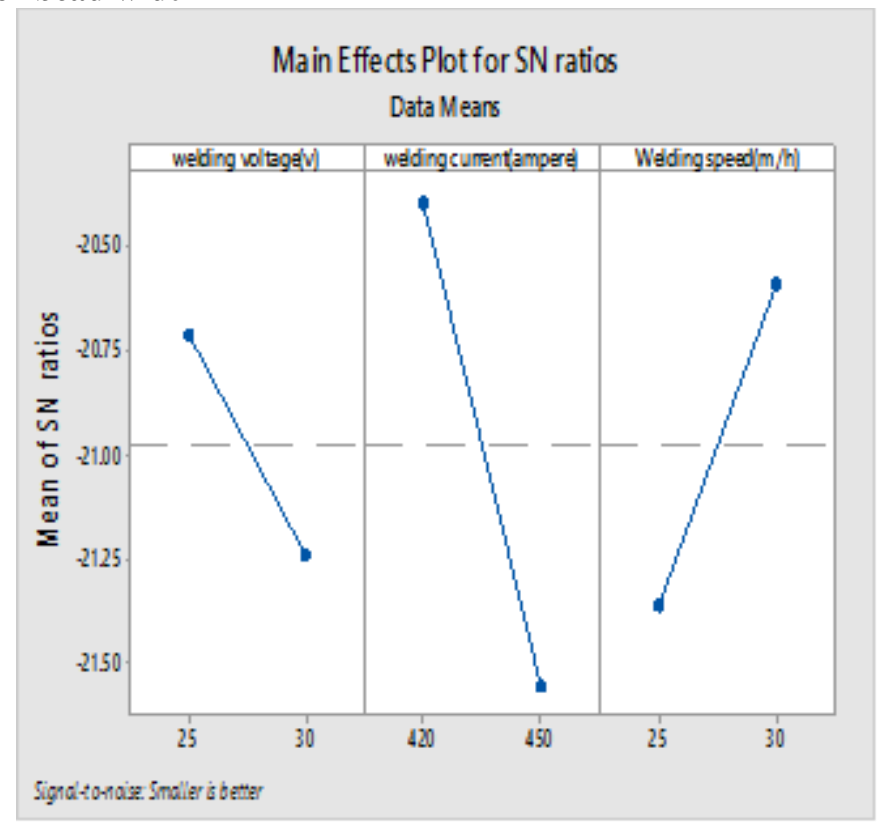

Figure 1 
Fig 1 shows the main effect plot for $\mathrm{S} / \mathrm{N}$ ratio for bead width. From the graph plot it is clear that values of response are decreased with increase in voltage and current and increase with increase in welding speed, as shown in fig.1.

\subsubsection{Main effect plot for bead hardness}

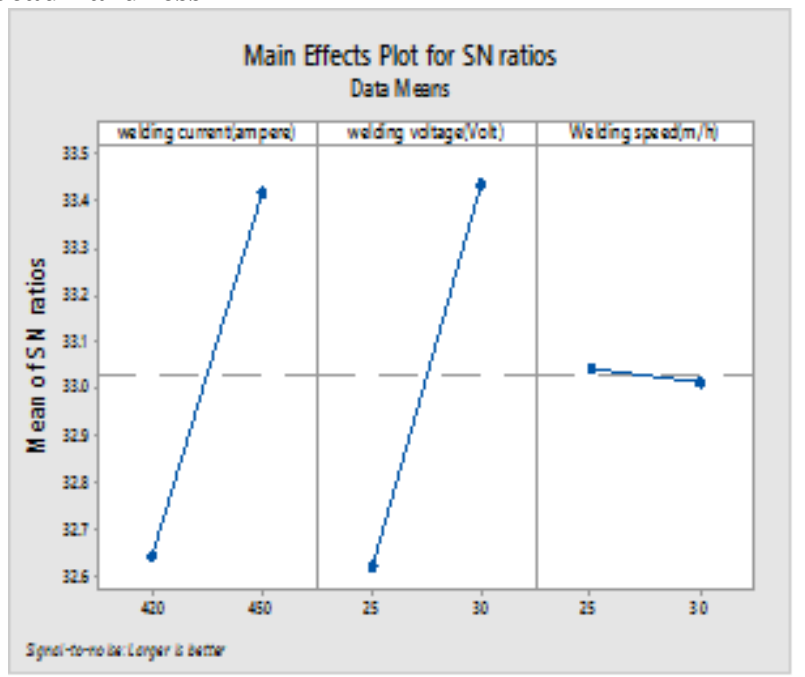

Figure 2

Fig 2 shows the main effect plot for $\mathrm{S} / \mathrm{N}$ ratio for bead hardness. From the graph plot it is clear that values of response are increased with increase in voltage and current and decrease with increase in welding speed, as shown in fig. 2

\section{Conclusions}

1. Decrease in welding voltage, decrease in welding current and increase in welding speed up to limit will decrease weld bead width.

2. Optimal parameter setting for smaller bead width is, voltage $=25 \mathrm{~V}$, current $=420 \mathrm{~A}$, speed $=30 \mathrm{~m} / \mathrm{h}$ for the specific test range in SS-304 and M.S. materials.

3. It has been analyzed that welding current is the most significant factor which affect the weld bead width.

4. Increase in voltage and current and decrease in welding speed up to limit will increase weld bead hardness.

5. Optimal parameter setting for higher bead hardness is, voltage $=30 \mathrm{~V}$, current $=450 \mathrm{~A}$, speed $=25 \mathrm{~m} / \mathrm{h}$ for the specific test range in SS-304 and M.S. materials.

6. It has been analyzed that welding voltage is the most significant factor which affect the weld bead hardness.

\section{References}

[1]. Y.S. Tarng, W.H. Yang \& S.C. Juang, (2000) "the use of fuzzy logic in the taguchi method for the optimization of submerged arc welding process", international journal of advanced manufacturing technology, vol. 16, 688-694.

[2]. N. Murugun, V. Gunaraj(2005) "Prediction and control of weld bead geometry and shape relationship in submerged arc welding of pipes", Journal of materials processing technology, vol.168, 478-487.

[3]. T. Kannan, N. Murugun(2006) "Effect of flux cored arc welding process parameters on duplex stainless steel clad quality", Journal of materials processing technology, vol.176, 230-239.

[4]. Deepak Choudhary, Sandeep Jindal and N.P.Mehta (2011)"To study the effect of welding parameters on weld bead geometry in SAW welding process", Elixir Mechanical Engg. Vol.40, 5519-5524.

[5]. Rati Saluja, K M Moeed(2012), "Modeling and Parametric Optimization using Factorial Design Approach of Submerged Arc Bead Geometry for Butt Joint”, International Journal of Engineering Research and Applications, ISSN: 2248-9622, Volume 2, Issue 3, 505-508.

[6]. Pranesh B. Bamankar, Dr. S.M. Sawant (2013), "Study of The Effect of Process Parameters on Depth of Penetration and Bead Width in Saw (Submerged Arc Welding) Process", International Journal of Advanced Engineering Research and Studies, EISSN2249-8974, 08-10.

[7]. Deepti jaiswal (2013) "Analysing the effect of parameters in multi pass submerged arc welding process" International journal on theoretical and applied research in mechanical engineering, vol.2, 60-70.

[8]. Pratik umrigar \& Sandip Chaudhry (2014) “Parametric optimization of SAW on SS-304" International journal for technological research in engineering, vol.1, issue.11, 1285-1293.

[9]. Farzeen Shahid, Abid Ali Khan \& Saqib Hameed (2015)“Mechanical and Micro structural analysis of dissimilar metal welds", IJRRAS, vol.25, Issue.1, 6-12.

[10]. Sukhbaj Singh, Jaswinder singh \& Viranshu kumar(2015) "Optimization of SAW parameters for joining SS-304 And MS 1018 dissimilar metal welding: A review" International journal of Technology innovation and research, vol.14.

[11]. A.M. Moshi, S.R. Bharthi, R. Rajeshkumar and R. Kumar (2016), "Factors influencing submerged arc welding on stainless steel: A review", ARPN Journal of engineering and applied sciences, volume.11, issue.2, 1237-1241. 